\title{
Cost-Utility Analysis of Fixed-Dose Combination of Indacaterol Acetate Glycopyrronium Bromide and Mometasone Furoate as a Maintenance Treatment in Adult Patients with Asthma Not Adequately Controlled with a Maintenance Combination of a Long-Acting Beta-Agonist and a High Dose of an Inhaled Corticosteroid Who Experienced One or More Asthma Exacerbations in the Previous Year
}

\author{
Pier Paolo Mangia ${ }^{1} \cdot$ Ottavio Gallo $^{2} \cdot$ Daniela Ritrovato $^{2} \cdot$ Lorenzo Pradelli $^{1}$
}

Accepted: 19 July 2021 / Published online: 31 July 2021

(c) The Author(s) 2021

\begin{abstract}
Background and Objective In asthma, symptom control is a primary goal that is not consistently met with available treatment options. The first commercially available fixed-dose combination in a single inhaler of a long-acting beta-agonist (indacaterol, IND), an inhaled corticosteroid (mometasone furoate, MF) and a long-acting muscarinic antagonist (glycopyrronium, GLY) has shown promising clinical results in phase III trials. The aim of the present study is to evaluate the cost-utility of IND/ GLY/MF fixed-dose combination relative to a combination of salmeterol/fluticasone and tiotropium or salmeterol/fluticasone or IND/MF in adult patients with asthma, from the Italian Health Service (NHS) perspective.

Methods A two-state and 4-week cycle Markov model was used to estimate lifetime clinical outcomes and costs. Patients entered the model in stable disease and could experience a non-fatal exacerbation event. The exacerbation rate is dependent upon the therapy a patient is receiving, as per the IND/GLY/MF clinical trials. The impact of each type of exacerbation is accounted by applying a utility decrement, obtained from the literature, and a treatment cost. Utility values were obtained from the EQ-5D questionnaires in the IND/GLY/MF clinical trials. Lifetime costs considered in the analysis were drugs and exacerbation management. Probabilistic sensitivity analyses were carried out, with the aim of evaluating the impact of uncertainty on input parameters.

Results IND/GLY/MF is associated with a higher quality of life [+0.25 quality-adjusted life-year (QALY)] than salmeterol/ fluticasone plus tiotropium, with an incremental cost of $-€ 3213.90$. The incremental cost-utility ratio indicates dominance. At a threshold of $€ 5000$ per QALY, IND/GLY/MF has nearly a $100 \%$ probability of being cost effective. IND/GLY/MF is associated with a higher quality of life (+0.21 QALY) than salmeterol/fluticasone, with an incremental cost of €2547.76. Incremental cost-utility ratio results in $€ 11,897$ per QALY. At a threshold of $€ 20,000$ per QALY, IND/GLY/MF has nearly a $100 \%$ probability of being cost effective. IND/GLY/MF is associated with a higher quality of life (+0.34 QALY) than IND/MF, with an incremental cost of $€ 4745$.91. Incremental cost-utility ratio results in $€ 14,088$ per QALY. At a threshold of $€ 20,000$ per QALY, IND/GLY/MF has nearly a $100 \%$ probability of being cost effective.

Conclusion The results indicate that IND/GLY/MF is cost effective against the considered comparators in a cohort representative of adult patients with asthma in Italy.
\end{abstract}

Extended author information available on the last page of the article 


\section{Key Points}

It is established that in patients with asthma, symptom control is a primary goal, as it leads to reduced burden to the patient and the healthcare system.

The first commercially available fixed-dose combination of a long-acting beta-agonist, an inhaled corticosteroid, and a long-acting muscarinic antagonist, a single inhaler of indacaterol/glycopyrronium/mometasone furoate, has been compared to both inhaled corticosteroid/longacting beta-agonist fixed combinations and to the use of an inhaled corticosteroid/long-acting beta-agonist plus long-acting muscarinic antagonist (separate inhalers).

On the basis of the clinical results, a Markov model has been fed with local Italian economic inputs.

Under the assumptions of the model, it is predicted that the new option is cost effective against existing alternatives.

\section{Introduction}

According to the Global Initiative for Asthma strategy document, asthma is a heterogeneous disease, normally characterised by a chronic airflow limitation. It is defined by a history of respiratory symptoms such as wheeze, shortness of breath, chest tightness and cough that varies over time and in intensity, along with a variable limitation of expiratory airflow. Restriction of airflow may subsequently become persistent [1].

Asthma can affect patients of any age, but is more common in children than in adults [1]. More than 358 million people worldwide suffer from asthma, with 400,000 reported deaths due to the disease in 2015. The prevalence of asthma varies between 3 and $20 \%$ in different countries [2], in Italy, the prevalence is around $6 \%$, thus affecting more than 3 million people [3-5].

The primary goal of asthma guidelines is to diagnose asthma correctly, achieve asthma control by reducing exacerbations, improve overall quality of life and educate patients on self-management of asthma. The longterm goals for asthma management are risk reduction and symptom control, leading to reductions in the burden to the patient and the risk of asthma-related death, exacerbation, airway damage, medication side effects and associated healthcare costs. Every guideline recommends a treatment step-up either by increasing the doses of inhaled corticosteroid (ICS) and/or the addition of controllers until patients with moderate-to-severe asthma achieve optimal disease control. Subsequently, patients should be frequently monitored to ensure that their disease is controlled with minimal drug therapy; once disease control is achieved, step-down treatment is recommended [1, 6-8].

In fact, according to Global Initiative for Asthma guidelines, the severity of asthma (mild, moderate or severe) is assessed retrospectively in relation to the level of treatment required to control symptoms and exacerbations and may change over months or years. Mild asthma is asthma controlled by step 1 or 2 of treatment, for example, with only medications as needed or with low-dose ICS or antileukotrienes. Moderate asthma is well controlled with step 3 treatment, for example, low doses of ICS/long-acting beta-agonist (LABA). Severe asthma requires step 4 or 5 treatment, for example, high doses of ICS/LABA, to prevent it from becoming "uncontrolled", or asthma that remains uncontrolled despite treatment.

Some recent Italian studies report that, despite current treatment, more than $50 \%$ of patients in Global Initiative for Asthma Steps 4 and 5 are not adequately controlled and have experienced one or more exacerbations in the previous year [9, 10]. Patients with uncontrolled asthma may downplay or underestimate the severity of their disease and are at a higher risk of exacerbation, hospitalisation or death [11-13].

It should also be noted that the cost of asthma increases gradually with the worsening of disease control. Almost half (46.2\%) of asthma expenditure in Italy is attributable to $25 \%$ of patients with the worst control [14]. In fact, according to the study carried out by Marcellusi and colleagues, the cost per patient ranges from $€ 126$ for intermittent asthma to $€ 2169$ for persistent severe asthma [15]. The once-daily Enerzair Breezhaler is the first LABA/long-acting muscarinic antagonist/inhaled corticosteroid fixed-dose combination available in Europe as a maintenance treatment for adult patients with asthma not adequately controlled with a maintenance combination of a LABA and a high dose of an ICS who experienced one or more asthma exacerbations in the previous year.

Two phase III studies, ARGON and IRIDIUM, investigated the effectiveness and safety of Enerzair Breezhaler. Regarding ARGON, in patients with uncontrolled asthma, single inhaler fixed-dose combinations of high-dose and medium-dose indacaterol/glycopyrronium/mometasone furoate (IND/GLY/MF) once daily (o.d.) were non-inferior to salmeterol/fluticasone twice daily (bid) plus tiotropium o.d. (SAL/FLU plus TIO). High-dose IND/GLY/MF o.d. 
demonstrated greater improvements in quality of life, lung function, asthma control and health status, and reduced moderate exacerbations [16].

With regard to IRIDIUM, the once-daily combination therapy of medium-dose and high-dose MF/IND/GLY, from a single inhaler, significantly improved lung function vs the respective once-daily MF/IND and high-dose twice-daily FLU/SAL, a well-established ICS/LABA combination. Both doses of MF/IND/GLY showed similarly large improvements in asthma control from baseline, with no difference between any of the treatments. The annualised rate of exacerbations was numerically lower with MF/IND/GLY vs the ICS/LABA comparators [17]. Through data derived from ARGON and IRIDIUM, published literature and regulatory disposition, we performed an economic analysis using a Markov model aiming to evaluate the cost effectiveness of Enerzair in treating patients with asthma who are uncontrolled despite treatment with LABA and a high dose of an ICS

\section{Methods}

\subsection{Model Description}

Asthmatic patients' clinical experience is simulated at a cohort level using a Markov model with two mutually exclusive states of health ("day-to-day symptoms", "death") over a lifetime horizon (50 years), until complete death of the cohort of patients. The simulated time is divided into equal cycles of 4 weeks to reflect the average duration of an asthmatic exacerbation: this choice is in line with recent economic assessments on asthma [18, 19]. The structure, shown in Fig. 1, is an adapted version of a cost-effectiveness model previously presented at the National Institute for Health and Care Excellence [20] in order to economically assess omalizumab in asthmatic patients with severe and persistent symptoms.

Patients enter the model in the "day-to-day symptoms" state, which takes into account the costs and quality of life associated with the treatments in question. During their stay in the "day-to-day symptoms", patients may experience one of three types of clinically significant severe exacerbations, which require treatment with oral corticosteroids, access to the emergency department or hospitalisation. Patients may also experience moderate exacerbations, defined when two or more of the following situations occur: (i) symptoms such as wheeze, cough, shortness of breath and tightness in the chest for at least 2 consecutive days; (ii) a $50 \%$ increase in the use of short-acting betaagonists compared with the reference value and (iii) a $20 \%$ decrease in the forced expiratory volume in $1 \mathrm{~s}$ compared with the reference value.

The rates of exacerbations, which depend on the therapy the patient is receiving, are extrapolated from the clinical trials of Enerzair, IRIDIUM and ARGON. The impact of each type of exacerbation is considered by applying a decrease in utility and a cost for the treatment of this exacerbation.

Death is an absorbing state of health, which includes both death from asthma due to exacerbations and general mortality by age and sex. However, because asthma deaths have not been reported in Enerzair's studies, nor, or only extremely rarely in the comparators' phase III studies (one death in QUARTZ and PALLADIUM studies for Atectura, no deaths in AUSTRI and VESTRI studies for SAL/FLU, no deaths in the PrimoTinA Asma study for TIO), asthma mortality has not been considered. A half-cycle correction
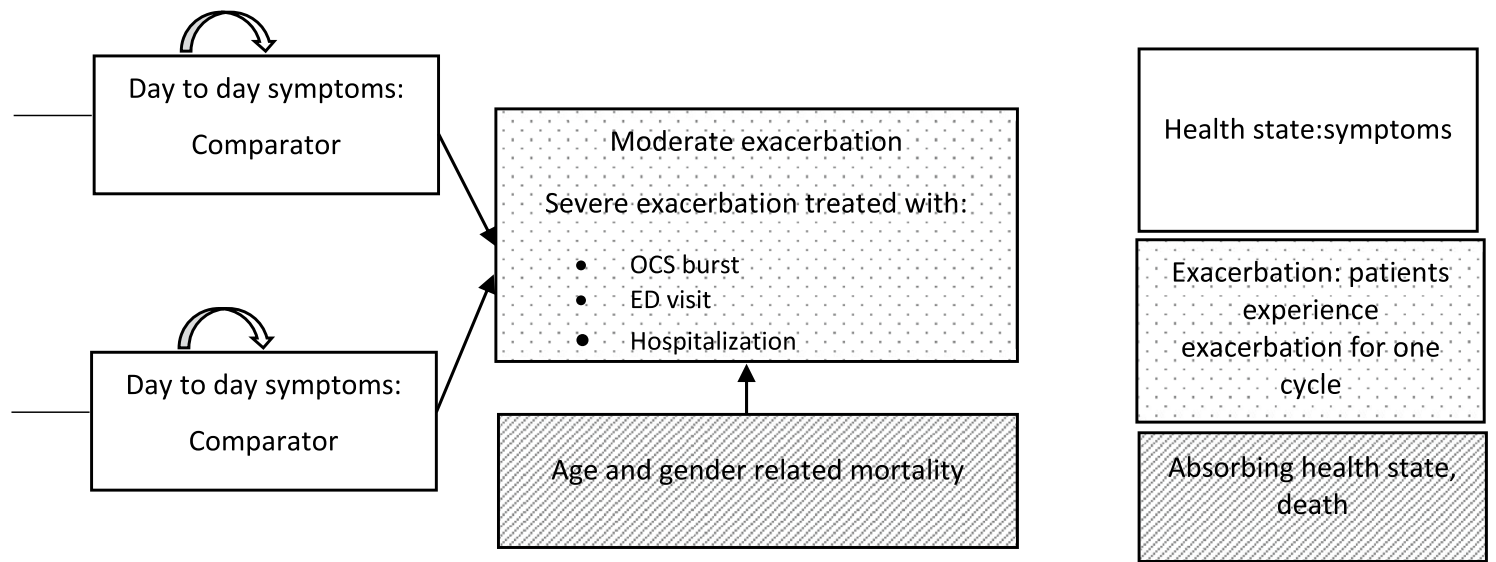

Fig. 1 Markov model structure. ED emergency department, $O C S$ oral corticosteroid 
is not applied, as the cycle length is considered short compared with the total simulation time.

\subsection{Assumptions}

- The model assumes that the clinical course of the disease is constant over the simulated period.

- Day-to-day symptoms are assumed to include both symptom-free periods and periods with non-clinically significant exacerbations.

- The model assumes that patients, regardless of treatment, do not discontinue treatment. This assumption is based on evidence that in clinical trials the probability of treatment discontinuation was negligible.

- Mortality from asthma exacerbations is assumed to be low and negligible and is not included-no asthma-related deaths were observed in the trials.

- As the trials did not measure it, the model assumes complete therapeutic adherence with Enerzair (i.e. 100\%) and all other treatments compared.

\subsection{Population}

The target population considered in the model is adult patients with asthma aged 18 years and older who are inadequately controlled despite treatment with high-dose inhaled corticosteroids and LABAs. The main characteristics of the population considered in the model are assigned on the basis of clinical trial data. The mean age was 52 and 53 years and the female proportion $62 \%$ and $63 \%$ in the IRIDIUM and ARGON studies, respectively.

\subsection{Time Horizon}

The model simulates the clinical experience of patients over a lifetime horizon (50 years); both costs and clinical effectiveness are discounted at a rate of $3 \%$ per year, after the first year.

\subsection{Treatments}

The model compares the costs and consequences of Enerzair, a fixed-dose combination of MF, IND and GLY. The model considers the following dose: IND/GLY/MF 150/50/320 $\mu \mathrm{g}$.

The following comparators are included in the model:

- Atectura ${ }^{\circledR}$ Breezhaler ${ }^{\circledR} 150 / 320 \mu$ g o.d. (MF/IND);

- Seretide ${ }^{\circledR}$ Diskus ${ }^{\circledR} 50 / 500 \mu \mathrm{g}$ bid (SAL/FLU);

- Salmeterol/fluticasone 50/500 $\mu \mathrm{g}$ twice daily plus Spiriva Respimat $^{\circledR}$ (TIO) $5 \mu$ g o.d. (SAL/FLU plus TIO)
Table 1 Exacerbation rate

\begin{tabular}{lll}
\hline Treatment & $\begin{array}{l}\text { IRIDIUM } \\
\text { No. of exacerbation/ } \\
\text { year (95\% CI) }\end{array}$ & $\begin{array}{l}\text { ARGON } \\
\text { No. of exacerba- } \\
\text { tion/year }(95 \% \\
\text { CI) }\end{array}$ \\
& & \\
\hline Severe exacerbations & & $0.36(0.28-0.47)$ \\
IND/GLY/MF & $0.26(0.22-0.31)$ & - \\
MF/IND & $0.33(0.28-0.39)$ & - \\
SAL/FLU & $0.45(0.39-0.53)$ & - \\
SAL/FLU + TIO & - & $0.32(0.25-0.42)$ \\
Moderate exacerbations & & \\
IND/GLY/MF & $0.48(0.42-0.54)$ & $0.34(0.30-0.38)$ \\
MF/IND & $0.60(0.54-0.67)$ & - \\
SAL/FLU & $0.78(0.69-0.86)$ & - \\
SAL/FLU + TIO & - & $0.54(0.47-0.61)$ \\
\hline
\end{tabular}

$C I$ confidence interval, $F L U$ fluticasone, $G L Y$ glycopyrronium, IND indacaterol, $M F$ mometasone furoate, $S A L$ salmeterol, $T I O$ tiotropium

Table 2 Utility values associated with the "day-to-day symptoms" status

\begin{tabular}{lll}
\hline Treatment & IRIDIUM & ARGON \\
\hline IND/GLY/MF & 0.775 & 0.755 \\
MF/IND & 0.759 & - \\
SAL/FLU & 0.766 & - \\
SAL/FLU + TIO & - & 0.742 \\
\hline
\end{tabular}

$F L U$ fluticasone, GLY glycopyrronium, IND indacaterol, $M F$ mometasone furoate, $S A L$ salmeterol, $T I O$ tiotropium

\subsection{Clinical Inputs}

\subsubsection{Exacerbation Rate}

Annual exacerbation rates (both severe and moderate exacerbations, Table 1) were extrapolated from the clinical studies. Among severe exacerbations, $90 \%$ are assumed to be treated with oral corticosteroids, $5 \%$ to require an emergency room and the remaining five to lead to hospitalisation, basing on previous economic research [21].

\subsubsection{Utility Values}

The utility values associated with the "day-to-day symptoms" status were extrapolated from the data of the EQ-5D questionnaires of the ARGON and IRIDIUM clinical studies and are shown in Table 2. Disutilities associated with the most clinically severe exacerbations (oral corticosteroid burst, emergency department visit or hospital admission) were derived from the literature (Table 3 ). These disutilities are then applied to the utility associated with day-to-day 
Table 3 Duration and disutility of exacerbations

\begin{tabular}{lll}
\hline Type of exacerbation & Disutility & Duration \\
\hline OCS burst & -0.1 & Assumed to be equal to cycle length \\
ED visit & -0.1 & \\
Hospital admission & -0.2 & \\
\hline
\end{tabular}

ED emergency department, $O C S$ oral corticosteroid

Table 4 Drug cost and dosage

\begin{tabular}{lllll}
\hline Treatment & Package cost, $€$ & Doses & Daily dose & Daily cost, $€$ \\
\hline Enerzair $150 / 50 / 320 \mu \mathrm{g}$ & 48.74 & 30 & 1 & 1.63 \\
MF/IND 150/320 $\mu \mathrm{g}$ & 28.43 & 30 & 1 & 0.95 \\
SAL/FLU 50/500 $\mu \mathrm{g}$ bid & 35.33 & 60 & 2 & 1.18 \\
TIO 5 $\mu$ g o.d. & 26.67 & 60 & 2 & 0.89 \\
\hline
\end{tabular}

$F L U$ fluticasone, GLY glycopyrronium, IND indacaterol, $M F$ mometasone furoate, o.d. once daily, bid twice daily, $S A L$ salmeterol, $T I O$ tiotropium

Table 5 Cost per type of exacerbation

\begin{tabular}{lll}
\hline Type of exacerbation & Cost, $€$ & Source \\
\hline Exacerbation with hospital admission & 2182.69 & {$[23,24]$} \\
Exacerbation with ED visit & 200.00 & {$[25]$} \\
Exacerbation with OCS burst & 36.49 & {$[26-28]$} \\
Moderate exacerbation & 36.49 & \\
\hline
\end{tabular}

$E D$ emergency department, $O C S$ oral corticosteroid

symptoms in cycles where an exacerbation is experienced, to account for the decrease in quality of life.

\subsection{Economic Inputs}

The cost categories considered in the model include pharmaceutical and exacerbation management costs.

\subsubsection{Pharmaceutical Costs}

The daily cost of drugs is calculated as the product of the unit cost and the dose consumed per day (Table 4). The unit cost of drugs is derived from the ex-factory price after mandatory discounts.

\subsubsection{Exacerbation Management Costs}

The cost of management of exacerbations has been quantified based on the type of exacerbation (Table 5):

- Exacerbations requiring hospitalisation: the cost of admission was valued as the average between the national tariff for DRG 96 and DRG 97 weighted for their relative frequency in Italy in 2018, according to data collected from hospital discharge records [23, 24].

- Exacerbations requiring emergency room access: the intensive short-term observation tariff, already used in the literature for analyses focusing on Italy, was used [25].

- Exacerbations requiring treatment with oral corticosteroids: literature data were used that quantified the cost per consumption of drugs for the management of exacerbations as $€ 21.09$ [26]; furthermore, it was assumed that the patient makes a visit to the general practitioner whose cost was valued at $€ 15.40$ on the basis of the DYSCO study [27] and is derived from the average of the cost of the outpatient visit and the cost of the home visit weighted for the respective frequency, updated to 2020 Euros with the ISTAT consumer price index [28].

- Moderate exacerbations: a similar cost was assumed as for severe exacerbations requiring oral corticosteroid treatment only.

\subsection{Sensitivity Analysis}

Uncertainties of input parameters, and their effect on estimated results, are evaluated through a probabilistic sensitivity analysis (PSA), conducted through 1000 simulations. A unique combination of parameters, randomly sampled from distributions within the confidence intervals for exacerbations and with a standard deviation of $\pm 10 \%$ of the mean value for utilities and costs, in the absence of a confidence interval, is used for each simulation. The PSA results are 
presented in the incremental cost-effectiveness plane and are used to estimate the cost-effectiveness acceptability curve (CEAC). The incremental cost-effectiveness plane shows the dispersion of the thousand results of the iterations, expressed as the respective incrementals of benefit [quality-adjusted life-year (QALY)] and cost of Enerzair compared to MF/ IND or SAL/FLU or SAL/FLU plus TIO. The acceptability curve, based on the 1000 iterations, indicates the frequencies (percentage) with which the ICER is lower than a certain threshold value; that is, it provides the probability that, for a given threshold value, Enerzair is more cost effective than MF/IND or SAL/FLU or SAL/FLU plus TIO.

\section{Results}

\subsection{IND/GLY/MF vs SAL/FLU Plus TIO}

IND/GLY/MF in asthma maintenance therapy is associated with an incremental efficacy of 0.25 QALY and a cost saving of $€ 3213.90$ compared with therapy with SAL/FLU in combination with TIO.

\subsection{IND/GLY/MF vs SAL/FLU}

IND/GLY/MF in asthma maintenance therapy is associated with an incremental efficacy of 0.21 QALY and a cost increase of $€ 2547.76$ compared with therapy with SAL/FLU, with a resulting ICER of 11,897.36 €/QALY gained.

\subsection{IND/GLY/MF vs MF/IND}

IND/GLY/MF in asthma maintenance therapy is associated with an incremental efficacy of 0.34 QALY and a cost increase of $€ 4745.91$ compared with therapy with MF/IND, with a resulting ICER of $14,088.45 € / Q A L Y$ gained.

\subsection{Sensitivity Analysis}

\subsubsection{IND/GLY/MF vs SAL/FLU Plus TIO}

The PSA, represented by the scatter plot in Fig. 2, shows robustness of the result to parameter uncertainty, as shown by the dense and symmetrical point cloud; the CEAC is not shown, as virtually all simulations indicate dominance.

\subsubsection{IND/GLY/MF vs SAL/FLU}

The PSA, represented as scatter plot in Fig. 3A, has consistent findings with the base case, with moderate dispersion. When shown as a CEAC (Fig. 3B), IND/GLY/MF has about $80 \%$ probability of being the most cost-effective choice at the willingness-to-pay threshold of $€ 15,000 / \mathrm{QALY}$.

\subsubsection{IND/GLY/MF vs MF/IND}

Furthermore, for this comparison, the PSA, represented as a scatter plot in Fig. 4A, has consistent findings with the base case, with moderate dispersion. When represented as a CEAC, it indicates that the treatment with IND/GLY/MF

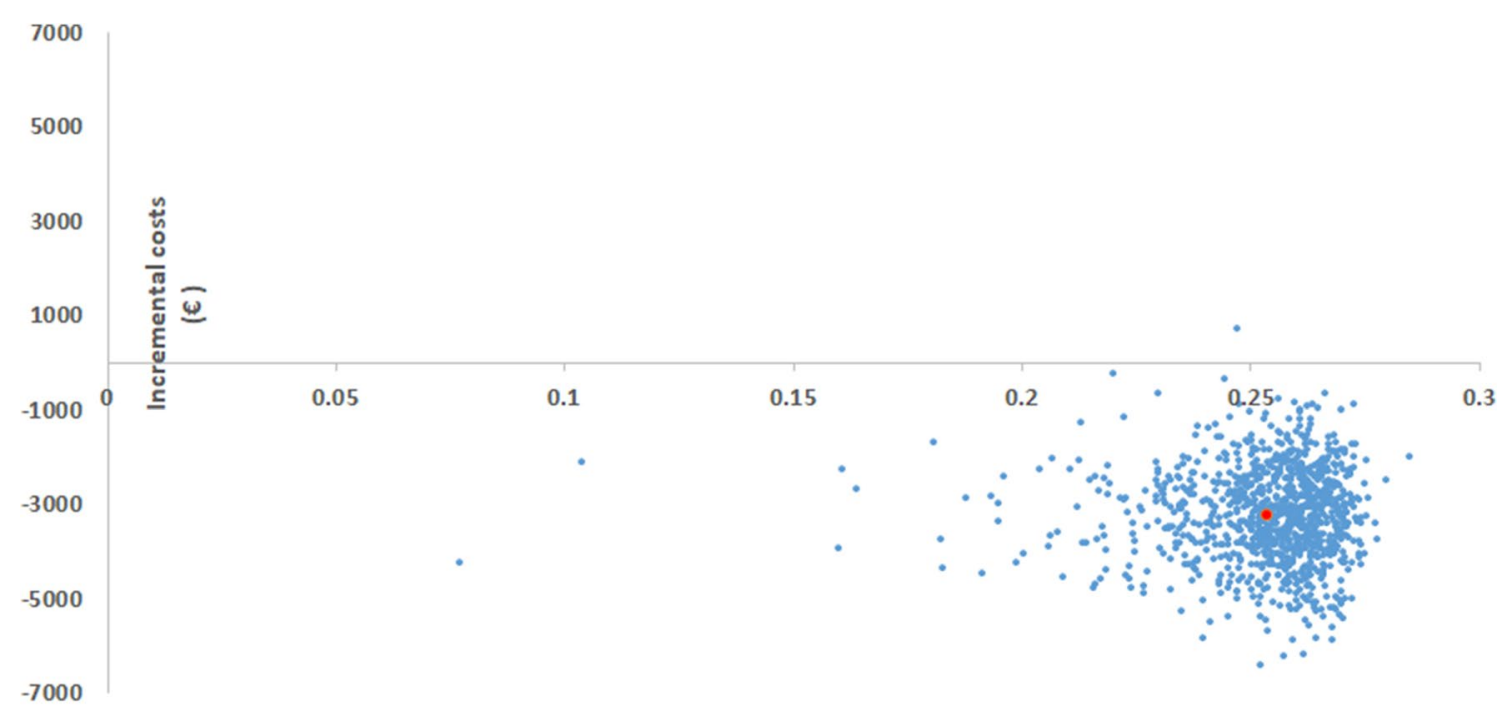

Incremental QALY

Fig. 2 Probabilistic sensitivity analysis scatterplot, indacaterol/glycopyrronium/mometasone furoate vs salmeterol/fluticasone plus tiotropium. $Q A L Y$ quality-adjusted life-year 


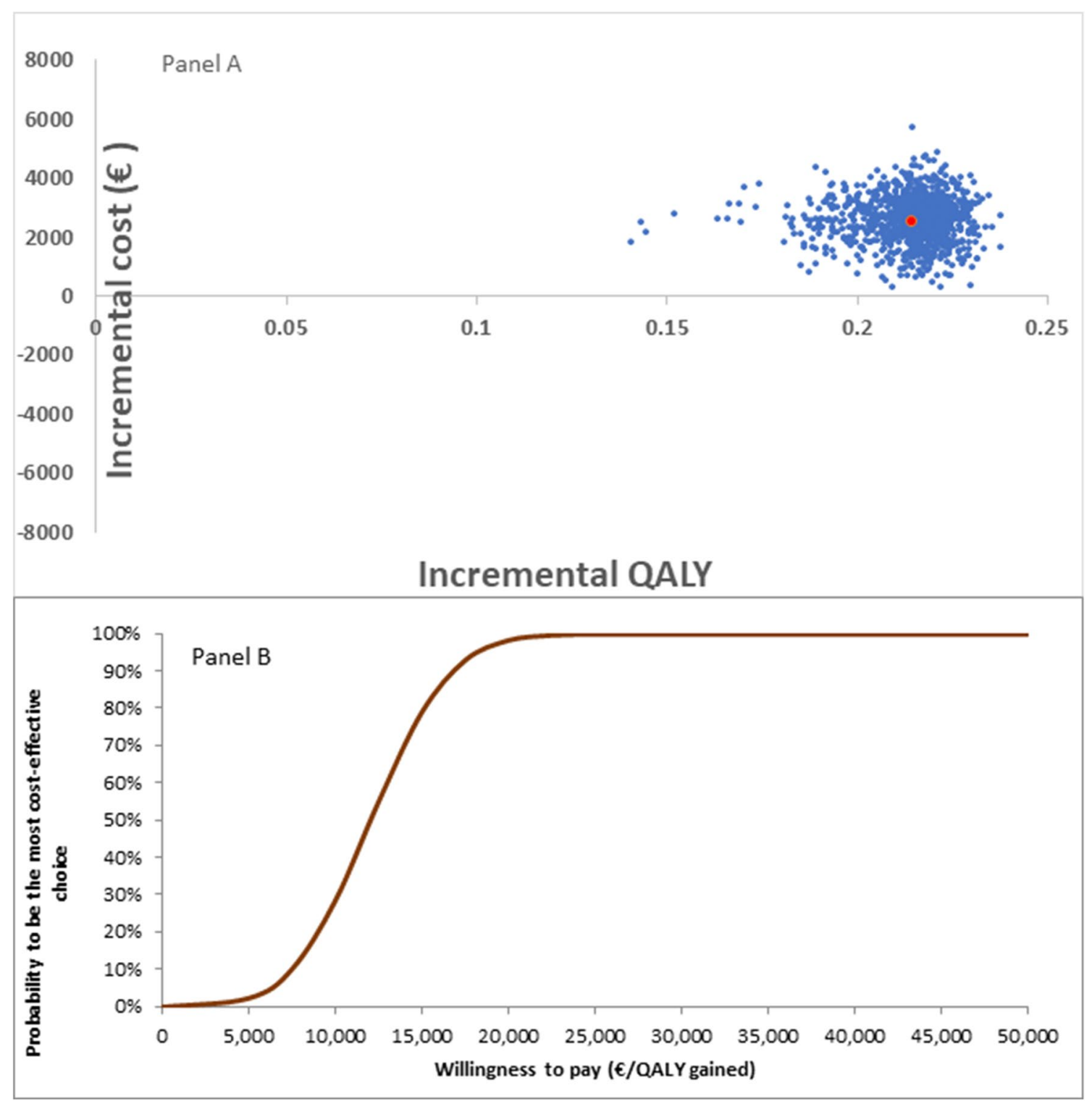

Fig. 3 Probabilistic sensitivity analysis for indacaterol/glycopyrronium/mometasone furoate vs salmeterol/fluticasone. A Scatterplot, B costeffectiveness acceptability curve. $Q A L Y$ quality-adjusted life-year

has about a $65 \%$ probability of being the most cost-effective choice at the willingness-to-pay threshold of $€ 15,000 / \mathrm{QALY}$ (Fig. 4B).

\section{Discussion}

Given the limited resources available to the healthcare system, decision making ought to be based on both evidence and rational economic analyses. Modeling the problem provides a deeper insight into the consequences of treatment. First, it enables a more accurate assessment of the differences between the drugs considered by attributing uncertainty intervals to predicted health outcomes and costs. Second, a model permits an increase in the time horizon beyond the duration of the trial, hence assessing the long-term implications. Last, a sensitivity analysis can be carried out to investigate possible thresholds, which might invert results on expected outcomes. With the help of such a model, we compared IND/GLY/MF and SAL/FLU plus TIO or SAL/FLU or MF/IND and investigated uncertainty regarding costs and effectiveness through a PSA. Our analysis shows that the fixed-dose combination of high-dose IND/ GLY/MF, when compared to SAL/FLU plus TIO, SAL/FLU, IND/MF or IND/GLY/MF is expected to be more effective and either cost saving or with an ICER well below conventional willingness-to-pay thresholds [29]. 
Fig. 4 Probabilistic sensitivity analysis for indacaterol/ glycopyrronium/mometasone furoate vs mometasone furoate/ indacaterol. A scatterplot, $\mathbf{B}$ cost-effectiveness acceptability curve. $Q A L Y$ quality-adjusted life-year

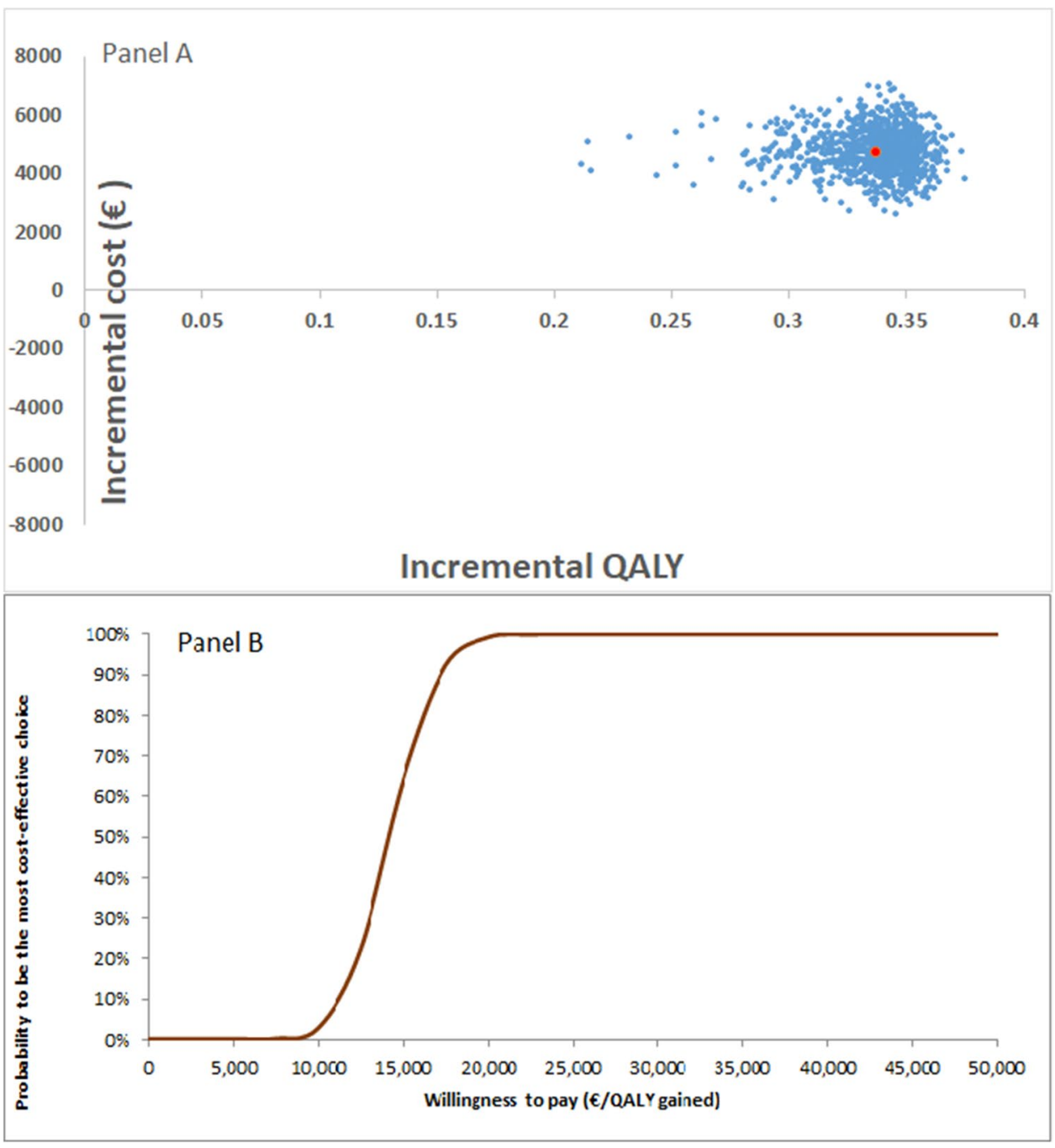

Potential limitations of this study are worth mentioning. First, effectiveness simulations are based on the short 24-week observation period set in the ARGON study, and are carried forward well beyond the time frame, being extrapolated to the rest of the analysis time frame. Given current data availability, it is not possible to compare these predictions with observed data, and the results should be interpreted keeping this in mind. Exacerbations were assessed as an exploratory endpoint and did not have the 52-week minimum follow-up, although greater reductions in moderate exacerbations with high-dose IND/GLY/MF vs high-dose SAL/FLU plus TIO were observed.

Another potential limitation is the missing input value available for compliance and adherence to the prescribed regimes; given the clinical relevance of the parameter, actual differences among treatment groups in the daily behaviour of the patients in this regard would change the results. Given the introduction of the new digital delivery device, we expect adherence to be favoured in the fixeddose combination of the high-dose IND/GLY/MF group, thus, setting it as maximal and equal for all comparators is very likely a conservative assumption introduced in the model. Despite the limitation described, we believe that this study may offer a guide for authorities to make more informed decisions regarding the control of national pharmaceutical expenditure.

\section{Conclusions}

Our results indicate that high-dose IND/GLY/MF is cost effective compared with SAL/FLU plus TIO or SAL/FLU or IND/MF, as maintenance treatment in adults who have had at least one asthma attack (exacerbation) in the last year and whose asthma is not controlled well enough with an inhaled LABA together with a high dose of an inhaled corticosteroid. 


\section{Declarations}

Funding This study was funded by Novartis Farma, Italy.

Conflict of interest LP and PPM (at the time of manuscript preparation) are employees of AdRes, which has received research grants from Novartis Farma. OG and DR are employees of Novartis Farma.

Ethics approval This is a secondary data analysis not requiring ethical approval.

Consent to participate Not applicable.

Consent for publication Not applicable.

Availability of data and material Not applicable.

Code availability Not applicable.

Author contributions All authors contributed to the study conception and design. Material preparation, data collection and analysis were performed by PPM, OG and LP. The first draft of the manuscript was written by PPM and all authors commented on previous versions of the manuscript. All authors read and approved the final manuscript.

Open Access This article is licensed under a Creative Commons Attribution-NonCommercial 4.0 International License, which permits any non-commercial use, sharing, adaptation, distribution and reproduction in any medium or format, as long as you give appropriate credit to the original author(s) and the source, provide a link to the Creative Commons licence, and indicate if changes were made. The images or other third party material in this article are included in the article's Creative Commons licence, unless indicated otherwise in a credit line to the material. If material is not included in the article's Creative Commons licence and your intended use is not permitted by statutory regulation or exceeds the permitted use, you will need to obtain permission directly from the copyright holder. To view a copy of this licence, visit http://creativecommons.org/licenses/by-nc/4.0/.

\section{References}

1. Global Initiative for Asthma. Global strategy for asthma management and prevention (2020). http://www.ginasthma.org (Accessed Sep 2020).

2. GBD 2015 Chronic Respiratory Disease Collaborators. Global, regional, and national deaths, prevalence, disability-adjusted life years, and years lived with disability for chronic obstructive pulmonary disease and asthma, 1990-2015: a systematic analysis for the Global Burden of Disease Study 2015. Lancet Respir Med. 2015;5(9):691-706.

3. Accordini S, Cappa V, Braggion M, et al. The impact of diagnosed and undiagnosed current asthma in the general adult population. Int Arch Allergy Immunol. 2011;155(4):403-11.

4. de Marco R, Cappa V, Accordini S, et al. Trends in the prevalence of asthma and allergic rhinitis in Italy between 1991 and 2010. Eur Respir J. 2012;39(4):883-92.

5. Guerriero M, Caminati M, Viegi G, Senna G, Pomari C. Prevalence and features of asthma-chronic obstructive pulmonary disease overlap in Northern Italy general population. J Asthma. 2019;56(1):27-33.
6. Stone B, Davis JR, Trudo F, et al. Characterizing patients with asthma who received Global Initiative for Asthma steps 4-5 therapy and managed in a specialty care setting. Allergy Asthma Proc. 2018;39(1):27-35.

7. Price DB, Román-Rodríguez M, McQueen RB, et al. Inhaler errors in the CRITIKAL study: type, frequency, and association with asthma outcomes. J Allergy Clin Immunol Pract. 2017;5(4):1071-81.

8. Suruki RY, Daugherty JB, Boudiaf N, Albers FC. The frequency of asthma exacerbations and healthcare utilization in patients with asthma from the UK and USA. BMC Pulm Med. 2017;17(1):74.

9. Corrado A, Renda T, Polese G, Rossi A, SERENA (Studio ossERvazionalE per il monitoraggio dell'asma non coNtrol1Ato)/AIPO Study Group. Assessment of asthma control: the SERENA study. Respir Med. 2013;107(11):1659-66.

10. Maio S, Baldacci S, Bresciani M, et al. RItA: the Italian severe/ uncontrolled asthma registry. Allergy. 2018;73(3):683-95.

11. Peters SP, Ferguson G, Deniz Y, Reisner C. Uncontrolled asthma: a review of the prevalence, disease burden and options for treatment. Respir Med. 2006;100(7):1139-51.

12. Katsaounou P, Odemyr M, Spranger O, et al. Still fighting for breath: a patient survey of the challenges and impact of severe asthma [published correction appears in ERJ Open Res. 2019 Feb 01;5(1):00076-2018-AUT]. ERJ Open Res. 2018;4(4):00076-2018.

13. Price D, Fletcher M, van der Molen T. Asthma control and management in 8,000 European patients: the REcognise Asthma and LInk to Symptoms and Experience (REALISE) survey. NPJ Prim Care Respir Med. 2014;24:14009.

14. Accordini S, Corsico A, Cerveri I, et al. The socio-economic burden of asthma is substantial in Europe. Allergy. 2008;63(1):116-24.

15. Marcellusi A, Viti R, Incorvaia C, Mennini FS. Costi diretti e indiretti associati a malattie allergiche respiratorie in Italia: uno studio probabilistico di cost of illness [Direct and indirect costs associated with respiratory allergic diseases in Italy: a probabilistic cost of illness study]. Recenti Prog Med. 2015;106(10):517-27.

16. Gessner C, Kornmann O, Maspero J, et al. Fixed-dose combination of indacaterol/glycopyrronium/mometasone furoate oncedaily versus salmeterol/fluticasone twice-daily plus tiotropium once-daily in patients with uncontrolled asthma: a randomised, phase IIIb, non-inferiority study (ARGON) [published correction appears in Respir Med. 2020 Dec;175:106186]. Respir Med. 2020;170: 106021.

17. Kerstjens HAM, Maspero J, Chapman KR, et al. Once-daily, single-inhaler mometasone-indacaterol-glycopyrronium versus mometasone-indacaterol or twice-daily fluticasone-salmeterol in patients with inadequately controlled asthma (IRIDIUM): a randomised, double-blind, controlled phase 3 study. Lancet Respir Med. 2020;8(10):1000-12.

18. National Institute for Health and Care Excellence. Technology appraisal guidance 431: mepolizumab for treating severe refractory eosinophilic asthma. Final appraisal determination (2016). http://www.nice.org.uk/guidance/TA431/documents/final-appra isal-determination-document (Accessed Sep 2020).

19. National Institute for Health and Care Excellence. Technology appraisal guidance 565: benralizumab for treating severe asthma (2019). http://www.nice.org.uk/guidance/ta565 (Accessed Sep 2020).

20. National Institute for Health and Care Excellence. Technology appraisal guidance 278: omalizumab for treating severe persistent allergic asthma (2019). http://www.nice.org.uk/guidance/ ta278 (Accessed Sep 2020). 
21. Institute for Clinical and Economic Review. Biologic therapies for treatment of asthma associated with type 2 inflammation: effectiveness, value, and value-based price benchmarks final evidence report December 20, 2018 Table 4.5. Exacerbation related inputs: SoC. https://icer.org/wp-content/uploads/2020/ 10/ICER_Asthma-Final-Report_Unredacted_08122020.pdf (Accessed Apr 2021).

22. Lloyd A, Price D, Brown R. The impact of asthma exacerbations on health-related quality of life in moderate to severe asthma patients in the UK. Prim Care Respir J. 2007;16(1):22-7.

23. Repubblica Italiana. Remunerazione delle prestazioni di assistenza ospedaliera per acuti, assistenza ospedaliera di riabilitazione e di lungodegenza post acuzie e di assistenza specialistica ambulatoriale [Remuneration of acute hospital care, hospital rehabilitation and chronic stay services, and specialty outpatient activities]. Gazzetta Ufficiale n. 23 del 28 gennaio 2013.

24. Ministero della Salute [Ministry of Health]. Rapporto annuale sull'attività di ricovero ospedaliero: dati SDO 2018. [Annual report on hospital activity: hospital discharge data 2018]. https://www.salute.gov.it/imgs/C_17_pubblicazioni_2898_alleg ato.pdf (Accessed Sep 2020).
25. D'Angela D, Carbone G, Casciato S, Spandonaro F. Analisi di percorsi, sistemi di finanziamento ed accreditamento [Analysis of pathways, financing and accreditation systems]. G Ital Cardiol 2014;15(2 Suppl. 2):22S-31S

26. Dal Negro RW, Distante C, Bonadiman L, Turco P, Iannazzo S. Cost of persistent asthma in Italy. Multidiscip Respir Med. 2016;11:44.

27. Garattini L, Castelnuovo E, Lanzeni D, Viscarra C. Durata e costo delle visite in medicina generale: il progetto DYSCO. [Duration and cost of GP visits]. Farmeconomia. Health Econ Ther Pathways. 2003;4(2):109-14.

28. Istituto nazionale di statistica (ISTAT). Rivaluta: rivalutazioni e documentazione su prezzi, costi e retribuzioni contrattuali [Official price index database and calculation tools by the National Insitute for Statistics]. http://rivaluta.istat.it:8080/Rivaluta/ (Accessed Sep 2020).

29. Messori A, Santarlasci B, Trippoli S, Vaiani M. Controvalore economico del farmaco e beneficio clinico: stato dell'arte della metodologia e applicazione di un algoritmo farmacoeconomico [Economic value of drugs and clinical benefit - methodological state of the art and application of a pharmacoeconomic algorithm] PharmacoEconomics-Italian Research Articles. 2003;5(2):53-67.

\title{
Authors and Affiliations
}

\author{
Pier Paolo Mangia ${ }^{1} \cdot$ Ottavio Gallo ${ }^{2} \cdot$ Daniela Ritrovato $^{2} \cdot$ Lorenzo Pradelli $^{1}$ \\ Lorenzo Pradelli \\ 1.pradelli@adreshe.com \\ 2 Novartis Farma, Origgio (VA), Italy \\ 1 AdRes Health Economics and Outcome Research, Via \\ Alfieri 17, 10121 Turin, Italy
}

